\title{
Clergy Perceptions of Mental Illness and Confronting Stigma in Congregations
}

\author{
Anthony David Campbell
}

check for updates

Citation: Campbell, Anthony David. 2021. Clergy Perceptions of Mental Illness and Confronting Stigma in Congregations. Religions 12: 1110. https://doi.org/10.3390/rel12121110

Academic Editors: Jeff Levin,

Magdalena Szaflarski and

Arjan Braam

Received: 1 October 2021

Accepted: 15 December 2021

Published: 17 December 2021

Publisher's Note: MDPI stays neutral with regard to jurisdictional claims in published maps and institutional affiliations.

Copyright: (C) 2021 by the author. Licensee MDPI, Basel, Switzerland. This article is an open access article distributed under the terms and conditions of the Creative Commons Attribution (CC BY) license (https:// creativecommons.org/licenses/by/ $4.0 /)$.
Department of Sociology, Anthropology and Social Work, Auburn University, Auburn, AL 36849, USA; adc0044@auburn.edu

\begin{abstract}
Mental illness and stigma are key concerns in congregations and represent important threats to community health. Clergies are considered influential in how congregants think about and respond to mental health issues, especially in African American congregations. In-depth interviews with 32 African American and White clergies were conducted to understand their unique perspectives on mental health and how they interact with their congregations based on those perspectives. Findings include six themes related to mental health stigma, namely, holistic definitions of health; African Americans and different conceptions of mental health (only reported by African American clergies); code words and language; depression as a special case; perceptions of mental health counseling and treatment; and clergy strategies for addressing mental health stigma. The clergies in this study recognized their influence on ideas related to mental health in their congregations, and most expressed active efforts toward discussing mental health and reducing stigma.
\end{abstract}

Keywords: clergy; congregations; religion; mental health; stigma; health; health communication

\section{Introduction}

Stigma of mental illness is considered a widespread threat to public health and communities in the United States (Parcesepe and Cabassa 2013; Casados 2017), and especially impacts racial and ethnic minority groups (Misra et al. 2021). Stigma leads to a number of harmful sequelae, including a tendency for individuals with mental illness to avoid seeking treatment (Corrigan 2004), being secretive about one's mental illness and withdrawing from others (Mayer et al. 2021), or only seeking spiritual interventions from clergies rather than from mental health professionals (Peteet 2019).

The connection of mental health and religion cannot be overlooked in a discussion of mental health stigma. Throughout history, conceptions of mental health and illness have been shaped by religious institutions and religious leaders (clergies). Adhering to a particular religious belief system produces a unique worldview through which mental health and illness are understood and given meaning-especially as influenced by the authority of the clergy (Oxhandler et al. 2018; Ward et al. 2013). Generally, research shows that religious adherence and attendance have positive effects on mental health, e.g., greater mental well-being (Corrigan et al. 2003), the receipt of social support (Rasic et al. 2011; Sternthal et al. 2010), increased coping skills (Rasic et al. 2011; Ward et al. 2013), and the prohibition of unhealthy behaviors while supporting healthy behaviors (Hill et al. 2007).

The specific context of this paper centers on Christian, predominantly Protestant, clergies and their leadership of congregations, which are defined here as organized, voluntary collections of people that regularly meet in a specific place for the purposes of religious worship and characterized by leadership, a formal name, and a shared identity (Cnaan and Curtis 2013). Religion may sometimes result in negative consequences for individuals with mental illness due to stigma perpetuated by harmful messages by some congregations and clergies. Congregations may become a source of stress for those struggling with mental health concerns through community criticism ultimately caused by 
stigma (Moreira-Almeida et al. 2006; Oxhandler et al. 2018; Sternthal et al. 2010). Speaking openly about mental health can lead to criticism and rejection from the religious community for deviating from the norm through attitude and behavior, causing increases in psychological distress (Peteet 2019; Sternthal et al. 2010).

Given the potential for both positive and negative influences of religion on mental health, clergies are in a key position to affect congregational views about mental illness and help-seeking. In fact, among US adults who experience any mental illness, 25\% turn to their religious congregation for help with their mental health issues (Wong et al. 2018). More specifically, clergies are often turned to for counseling in times of emotional or mental distress (Hays 2018). African American communities are even more likely to rely on faith leaders, with one study showing that nearly $40 \%$ of African Americans consider clergies as their primary source of support with depression (Anthony et al. 2015). Clergies are respected community members who serve as the mouthpiece of their religious organizations and thus convey institutional and denominational views about mental illness (Ward et al. 2013). The fundamentalist ideology that predominates certain religious traditions leads to congregation members accepting their clergy's opinions as correct due to their unquestioning authority, even if they include stereotypes and unhealthy beliefs (Peteet 2019). Additionally, research shows that Protestant and non-denominational Christians are more likely to believe in historical views of mental health, such as the etiology of mental health issues being spiritually oriented (Wesselmann and Graziano 2010).

Due to clergies holding this sort of authority and influence over congregation members' lives, how clergies respond to people's concerns impacts the congregants' perceptions and behaviors toward their own health and mental health (Anshel and Smith 2014; Ward et al. 2013; Bopp et al. 2013). Additionally, due to their considerable influence, clergies are often looked to for facilitating interventions to promote mental health in faith communities (Peteet 2019; Wong et al. 2018).

Two theoretical frameworks, the health belief model and the socioecological model, are helpful for understanding clergies, their health beliefs, and how they enact those beliefs in their communication. Using the health belief model, understandings of how clergies discuss health and mental health should be informed by their beliefs about risks and benefits of behaviors related to health and illness and their ability to effectively respond to health threats (Skinner et al. 2015; Janz and Becker 1984). Applied to clergies, the health belief model predicts that clergies will communicate with their congregations about health matters if they believe or have awareness that there is a perceived risk of mental illness in their congregation and that mental illness has serious consequences. Additionally, communication or behavior available to clergies might help reduce the risk or severity of mental illness in their members, and the potential benefits of taking such actions outweigh the costs of doing so (Skinner et al. 2015). Based on this model, the degree to which clergies think and communicate about mental health should be based on the effects those issues have on their congregations, as well as calculations of the risks and benefits of addressing them.

To situate this individualistic theoretical perspective within the broader context of congregations and communities, the socioecological model is applied (Bronfenbrenner 1979). The socioecological model is used and modified by many scholars to understand clergies' individual beliefs and resulting behaviors in the context of multiple layers of social complexity (Campbell et al. 2007; Webb et al. 2011). Essentially, how clergies communicate about health should vary based on a wide variety of factors, including intrapersonal characteristics (knowledge, beliefs, attitudes, and experiences), combined with their interactions with increasing levels of social structures (families, education, congregation, denomination, theological factors, larger cultural concerns, etc...). Clergies are a heterogenous group with many individual differences situated in wide-ranging socioecological contexts. These differences determine whether clergies engage in health communication and promotion and the extent to which they are involved in that role (Webb et al. 2011). Therefore, socioecological models have been used extensively to understand how multiple levels of social structure 
influence individual behaviors regarding complex health problems (Kousoulis and Goldie 2021), and specifically applied to clergies (Baruth et al. 2015; Payán et al. 2021).

African American congregations specifically have been the focus of much of the literature on mental health and congregations. There is an abundance of information on African American congregations but not the larger, more general, population of congregations. Much research on the role of African American clergies in health is focused on the mental health outcomes of congregants (Stansbury and Schumacher 2008). Levin (1984) suggested that the medical profession was less resistant to clergies providing mental health services than primary care delivery as it was seen as more compatible with religion. African American ministers may also view mental health as being more compatible with their role than physical health and possibly believe that they are better able to assist with mental health concerns. Additionally, African American congregation members may be pulled toward ministers, in part due to the historical role of ministers as counsel, and pushed away from professional mental health providers due to a variety of factors, such as "stigma, cost, mistrust, a philosophy of self-reliance" (Neighbors et al. 1998, p. 770). Furthermore, the Black church is often viewed as a potential messenger for reducing mental illness stigma due to its ability to provide culturally appropriate and trusted information to congregations (Campbell and Winchester 2020).

The common belief among African American clergies and congregations that spiritual, physical, and mental health are interconnected is also an important reason for a focus on mental health services. Holt and McClure (2006) find that the most frequent theme in their qualitative interviews with African American church members and pastors is the belief that mental health strongly influences physical health. West and colleagues (West et al. 2006) find that pastors are also more likely to address health problems that they believe are behaviorally based, such as sexual behavior, stress, and tobacco use. They also report that the most commonly cited health-related problems in their congregations are stress, overweight, obesity, tobacco use, and substance abuse, all issues that are arguably linked to behavioral, emotional, or spiritual disturbance.

Ultimately, there has been a long history of research pertaining to religion and mental health (Levin 2010), especially in African American communities in specific regions of the US (Wong et al. 2018). However, there have been few studies that focus on diverse samples of clergies, their beliefs on mental health and stigma, or how they develop and enact those beliefs in their communications within their churches. This qualitative study aims to add to the existing literature regarding mental illness and stigma in religious congregations from the unique perspectives of a diverse sample of clergies, both Black and White faith leaders from a variety of Christian denominations.

\section{Methods}

A qualitative approach was used in this study to elicit clergies' perspectives on health in congregations. Through this qualitative approach, participants elaborated extensively on their thoughts and experiences specifically related to mental health.

\subsection{Participants}

Thirty-two participants were selected from the population of lead clergies in Jefferson County, Alabama through a respondent-driven sampling procedure (Salganik and Heckathorn 2004). This sampling technique is often used to obtain samples consisting of individuals from special populations. For example, after conducting two pilot interviews, the names of six clergy members were suggested as potential participants. This allowed access to clergies who are viewed as knowledgeable on the topic of health and increased the likelihood of participation in interviews. A second phase, theoretical sampling, was used later in the process to diversify the sample. From the study population, African American and White clergy members were selected to create a comparative sample. Criteria for inclusion in the study included the following: (1) identifying as African American (or 
White) and (2) being the primary clergy of a predominately Black (or White) faith-based organization in Jefferson County, Alabama.

Participants were 63\% African American, 81\% male, ranging in age from 34 to 64 years, highly educated, and representative of a variety of Christian denominations and community characteristics (see Table 1).

Table 1. Characteristics of participants and congregations/churches $(n=32)$.

\begin{tabular}{|c|c|}
\hline & $\begin{array}{c}\text { Mean (Median, Range) or Frequency } \\
\text { Distribution }\end{array}$ \\
\hline Age & $51(45,34-64)$ \\
\hline \multicolumn{2}{|l|}{ Race } \\
\hline Black & 20 \\
\hline White & 12 \\
\hline \multicolumn{2}{|l|}{ Gender } \\
\hline Man & 26 \\
\hline Woman & 6 \\
\hline Number of Years in Ministry & $24(15,8-51)$ \\
\hline \multicolumn{2}{|l|}{ Congregational Type } \\
\hline African Methodist Episcopal (AME) & 4 \\
\hline African Methodist Episcopal Zion (AME-Z) & 1 \\
\hline Christian Methodist Episcopal (CME) & 3 \\
\hline Church of Christ (COC) & 1 \\
\hline Church of God (COG) & 1 \\
\hline Church of God in Christ (COGIC) & 2 \\
\hline Episcopal (E) & 3 \\
\hline Missionary Baptist Church (MBC) & 2 \\
\hline National Baptist Convention NBC) & 3 \\
\hline Presbyterian Church USA (PCUSA) & 1 \\
\hline Roman Catholic (RC) & 1 \\
\hline Southern Baptist Convention SBC) & 3 \\
\hline United Methodist Church (UMC) & 4 \\
\hline Non-denominational (ND) & 3 \\
\hline Congregation Size (Avg weekly attendance) & $340(175,36-2100)$ \\
\hline Congregation Annual Budget & $\left(\mathrm{USD}_{100,000-5,000,000)^{1}}\right.$ \\
\hline Number of Paid Staff & $10(7,2-76)$ \\
\hline
\end{tabular}

${ }^{1}$ Mean unavailable due to incomplete data.

\subsection{Procedure}

In-depth interviews were used to elicit participants' perspectives related to health in their capacities as clergies. Following a semi-structured interview guide, participants were asked to define health, identify health concerns facing their congregations, discuss the role of clergies and churches in health, and describe how they discuss and respond to health issues as clergies. An initial sample of questions included in the current interview guide included, but was not limited to, the following: "Tell me about your congregation."; "How do you define health?"; "How open do you think your congregation is to hearing about health issues from you as a member of the clergy?"; "What are some of the important health issues facing your congregation (and community)?"; "What health topics are not appropriate for you to talk about in your sermons?"; How are you involved in addressing concerns about health in your congregation?; and "If I asked your congregation members today about what makes you different from other clergy, what would they say?"

Participants were asked to elaborate on concepts that needed clarification or expansion, and this paper describes common references to mental health and related emergent themes. In-person interviews were conducted at locations chosen by interviewees, typically private offices. Interviews lasted approximately $75 \mathrm{~min}$, on average. Interviews were audio- 
recorded and transcribed verbatim. Study procedures were approved by the institutional review board at the University of Alabama at Birmingham.

\subsection{Data Analysis}

Transcripts were analyzed using an inductive method, which involved the identification of codes using line-by-line and focused strategies. Qualitative concepts and themes were identified and analyzed according to modified grounded theory principles. In the initial coding phase, a code was assigned that best described the data line-by-line. This initial coding strategy was used to make narrative data logistically manageable. The lineby-line coding process helped to crystallize key concepts that otherwise would remain diffuse in the extensive narrative text. These initial codes were used to start illuminating potential conceptual categories. Through analyzing these codes, theoretical memos were written to reflect on overall observations, which helped facilitate the emergence of social processes within the narrative data. Next, through focused coding, recurrent concepts were arranged into codes that were more "directive, selective, and conceptual" than initial coding (Charmaz 2006, p. 57). These codes classified the data according to emerging themes. Throughout the coding processes, codes were trimmed, renamed, and merged into larger categories that corresponded to themes in the data. This coding process was not a simple grouping procedure. By using the technique of constant comparison, a dynamic between codes, categories, and themes could be generated, where new gaps were identified and concepts were further refined throughout the analytic process.

\section{Results}

Mental health and stigma emerged as overarching themes in participant interviews. The following sections outline the results by six categories or sub-themes that emerged to contribute to the larger theme of mental health and stigma. These sub-themes include the following: (1) holistic definitions of health; (2) African Americans and different conceptions of mental health; (3) code words and language; (4) depression as a special case; (5) perceptions of mental health counseling and treatment; and (6) clergy strategies for addressing mental health stigma. Participants' names are replaced with pseudonyms (Alabama county names), and race, gender, and denomination are indicated at the first mention of participants and representative quotes as they appear below.

\subsection{Holistic Definitions of Health}

Although mental and emotional dimensions were included in clergies' definitions of health, there was variation in how much mental health received further elaboration. Some pastors readily discussed mental health and illness as a central issue in their congregations, while others only discussed the topic when asked specifically about it. In either case, mental health represented an area in which participants were highly interested. Remarkably, once prompted about mental health, clergies often spoke with even greater concern and with more elaboration about mental health than physical health issues.

Although mental health and illness were not discussed exclusively in interviews with clergies of predominately African American congregations, those clergies' responses were even more detailed and indicative of the extent to which they had been exposed to such issues in their congregations. For example, Reverend Baldwin (White male UMC) shared how his conceptions of health have evolved after his multiple-year tenure at a mostly Black congregation. He said "“'I think if you would have asked me that question before I came here, I would have defined health as your blood readings, blood pressure, diabetes and blood sugar, weight, those sorts of things which are certainly a part of health. I have been amazed at how many people in our neighborhood deal with mental health challenges. And so, I would look at health both from a physical and mental health component now. So, I guess I look at health in a really holistic way."

Reverend Shelby (Black female, CME) explained that "most people define mental health in terms of a pathology of mental health. So, people would think of mental health 
as when someone is exhibiting extreme symptoms." Several other pastors mentioned the tendency of people to focus on the extreme examples of mental illness and that this is at the expense of overlooking more common mental health issues, such as depression and anxiety. Stigma of mental illness was identified as the culprit for these common misperceptions. Some of the most common points about the stigma of mental health discussed by pastors are combined in the following quote from Reverend Calhoun (Black male NBC):

When I was growing up, when someone used the term 'mental illness' that was a sign that that person was crazy. I think we've learned more and look at these things differently. But I think stigma is still attached to mental illness. Mental illness is such a nebulous term. It's a wide range; it could be anything.

\subsection{African Americans and Different Conceptions of Mental Health}

Most African American clergy participants discussed how the topic of mental health is viewed differently in the Black community. Beginning with a heavy sigh, Reverend Shelby prefaced her comments with "this whole issue of mental health in the African American community is a big, big issue". There was a similar response from several participants, and some seemed to anticipate questions about mental health specifically. Reverend Shelby continued to connect how historical events and current circumstances have produced what she calls a cultural form of post-traumatic stress disorder. She provided the following extensive commentary and excellent summary of this issue:

Well, the African American community, particularly as it evolved, I think postslavery, we now will talk about it in terms of post-traumatic stress syndrome or post-traumatic slave syndrome, some writers have called it. At any rate, in coming out of that experience where vulnerability was a liability, if you were weak or if you showed any kind of ... there was a sense of I've gotta be tough. What has evolved in the present-day African American community is a real taboo in terms of talking about mental health issues in a genuine way.

Several more participants discussed the stigma associated with mental illness, specifically addressing the pervasiveness of stigma in the African American community and especially the church. Reverend Calhoun explained that "In the Black community, there's not a lot of open discussion about mental health. It gets a bad rap." Multiple pastors talked about the commonly held traditional belief in their communities that strong faith is a preventive factor or a cure for mental illness. Pastor Lawrence (Black male AME) talked about a 'super-Christian mentality' in which Christians often believe they should not experience mental health problems. He relayed a common belief system, "Christians don't have issues like non-Christians. Whatever it is God will fix it. When in reality, God has blessed us with human beings who are trained to help us with things where we can't help ourselves. So, a lot of times, mental illness is overlooked in the church." He further explains:

Some people are clinically depressed in the church but are ignored. People who are grieving tremendously and never get grief counseling because in the African American community, African Americans for the most part are accustomed to suffering. So, understand that I'm speaking specifically to my, to our culture here. So, we're people who are accustomed to suffering and then there was this stigma if you need to sit down and talk with anybody or if you need any kind of medication, it deems you as being, you know, crazy and psychotic.

\subsection{Code Words and Language}

The majority of participants shared the view that mental illness stigma is often conveyed through the use of code words for mental illness and language that is derogatory or shaming. Reverend Blount's (Black female AME-Z) comments below provide a representative summary of what many, especially African American participants, indicated.

When I was a kid, I could remember code words like “Oh, they're just special or she's just touched." You know, code words, which really was the culture's 
way of putting someone in a category but not necessarily investing anything in getting them the help they needed. And so now we have a culture that just kind of assumes to be "crazy" - that's what I hear people say when I say have you thought about getting counseling or getting some therapy—“well I'm not crazy". It's just too vulnerable, too much of a vulnerable place. And I think that we do recognize now that somebody's just not crazy or touched but they may be schizophrenic, they may be bipolar. But in the church, it's not something we have historically not talked about.

The stigma of mental illness is communicated and strengthened through language. For example, several participants further discussed the dreaded term 'crazy' as a label to be most avoided. Reverend Clarke (Black female AME) shared:

... as African Americans-we don't—we've always taken care of people who had mental health issues but we've never talked about it and we've never kind of dealt with that part." When asked why this is, she responded, "Basically, because, well, it's crazy. You're crazy. And nobody wants to be crazy. [Laughs] Nobody wants to be crazy and nobody wants to be shunned because of that.

Pastor Pickens (Black male ND) talked about how common mental illness is in the African American community but at the same time confirmed the stigma associated with it. He said "They even call it the crazy check. That's why people are so embarrassed, when you get a disability check for your mental illness." All participants mentioning stigma of mental illness indicated that this prevents people from seeking the help they need.

The word psychotic should also be avoided as it is used as a near synonym for crazy. When asked about psychotic disorders, Calhoun quickly responded "Oh, we don't even talk about that! I mean, what is that? I am serious that you don't hear that language in the Black community. It just carries a different connotation to it." Calhoun, fully understanding what the term psychotic meant, described how stigmatizing severe and persistent mental illnesses, such as schizophrenia, can be. This language and the social consequences of stigma have produced a deeply embedded cultural norm of avoiding public discourse on mental illness.

\subsection{Depression as a Special Case}

More specifically, depression was as a special case that clergies wanted to differentiate from the broader discussion of mental illness. Pastors noted changes around how people view depression in the church. For instance, Reverend Calhoun discusses how perceptions about depression have changed and how he believes depression has become more normalized:

Depression has taken on a different tone to it now. Just the conversation around depression is different. More people are making it known that they have lived with or suffered through depression, people that we know, notable people. So, it doesn't get the bum rap that it used to get. So, if someone gets depressed, then the key is getting them the help they need.

Brother Montgomery (White male SBC) shared how his interpretation of depression has changed over time. He said that he had never experienced depression before and due to that, he believed that depression in others was caused by a lack of a robust spiritual life. However, after exposure to family members who experienced severe depression, he began to see that there was something else happening. Based on his observations, he now sees depression as a chemical imbalance that often requires medication. Only a small group of participants reported that mental health issues are openly discussed in their congregations. Reverend Marshall (White male E) explained that due to the progressive, more liberal leaning of the Episcopal Church specifically, the stigma of mental health is not as much of a factor as in more conservative traditions. However, Pastor Winston (SBC White male) asserts his perception that mental health discussions are much more accepted in the context of churches in general today. He offers the following explanation: 
I think the church is ahead of society. I think that in one sense, I don't think that the church sees depression as a weakness. I think society does. I think the willingness to admit to depression is probably higher in a church where you have a small group of people who have become community where someone can say "I'm struggling right now" but out there in the secular world he's macho and he can't do that.

\subsection{Perceptions of Mental Health Counseling and Treatment}

The concerns among clergies about mental health issues translated into a variety of views about counseling and treatment. Pastor Winston (White male SBC) reports that his large Baptist church is highly involved in serving the emotional and mental health needs of his congregation through an established counseling program. He admits that the program has been criticized at times for possibly crossing the line into the territory of professional mental health providers. Another pastor, Reverend Pickens (Black male ND), who stated that he trained as a social worker, was quite enthusiastic about his vision of opening a counseling center as part of his church ministry. He explained that "every church needs to have a counseling center in it just so people who are going through it [emotional/mental health concerns] can come in and speak to a counselor or somebody about their issues."

Several participants emphasized how they would refer people with mental health concerns to appropriate professionals in the community. Pastors were generally focused on their spiritual roles in mental health concerns and expressed an awareness of limitations of where a person's needs exceed their capacities. Reverend Lawrence shared how he frequently discusses mental and emotional health with his members in a pastoral counseling capacity. He recognizes that "there's things that some people might not want to talk with me about and there's some things that go beyond my level of training ... Sometimes we find the solution in my office or sometimes there's a recommendation that they need to go and seek a professional counselor."

Other participants were more reticent about their relationship to counseling. Reverend Houston (Black male MBC) recognized counseling as a potentially good thing but added

I don't know how successful all counseling is. I don't know how many of us would actually go to a counselor or a person who we really don't know and share everything. Some of us would. Some of us do ... We could probably do a much better job on mental health now that I think about it.

Houston elaborated that part of the reason for the hesitance about counseling in his congregation is not having enough information about how it works and its benefits in addition to the need for it to come from a trusted source. He added, "It can't just be anybody. If it's the wrong person up there it could do more harm than good." Reverend Marion (Black male COGIC) was more adamant about not engaging in counseling of mental health issues and cited "the laws saying that unless you have been certified as a psychologist or sociologist you are not to counsel anybody under the realm of mental issues." When asked how he responds to people who come to him with mental health concerns, Reverend Marion expressed that it is important "to get them to the emergency room, you know, where the health care facility is going to be forcing you to do something, if nothing else but put them in a unit for observation." This excerpt illustrates the focus of some pastors on the more severe cases of mental illness. Marion's statements suggest that there are opportunities for providing accurate information about the range of available mental health treatment to congregations, which could improve the chances of people getting the support they need.

The hesitations and misconceptions expressed by Houston and Marion are not surprising given the mistrust of health providers among African Americans. Several Black pastors discussed this issue, as typified by Reverend Shelby saying "I'm sure you are aware of mistrust issues of healthcare and you know most of those get tracked back to the Tuskegee Experiment." Several participants alluded to the Tuskegee Syphilis Study, a United States Public Health Service research program in the 1930s that unethically involved unknowing 
African American men to follow the effects of untreated syphilis. This egregious public health atrocity left a lasting impact on African American communities and led to the distrust of medical research and medicine in general. This historical event has become a central part of understanding African American religion and health in the United States (Laws 2018). Furthermore, Reverend Shelby also explains that some of the mistrust in the mental health system specifically lies with African Americans' views of psychiatric medications. The following quote relates to this issue:

I think most African Americans just get really uneasy when medications are prescribed. And you know high blood pressure, diabetes, heart conditions, those all have a kind of visceral physical impact. If my blood pressure is high, I'm probably gonna be dizzy. And so, taking that kind of medication you probably get less resistance. But when "I just don't feel good" and "I just don't have the energy" and then you start talking about taking an antidepressant and then it's like "What? Wait, wait, I'm not that bad! You're trying to get me to take some drugs! Why?" You know, the mistrust issues begin to bubble over.

\subsection{Clergy Strategies for Addressing Mental Illness Stigma}

Clergies believed that having open discussions about mental illness is key to addressing the stigma associated with mental illness. They viewed such discussions as compatible with their clergy role and as a vital part of addressing health from a holistic standpoint. Some of the health communication strategies reported by clergies are applicable to mental health, including the use of relevant biblical support; use of language (to combat stigma); and 'keeping it real, relevant, and relational' (addressing everyday needs and concerns of congregants).

Pastor Baldwin discussed the idea of mental illness stigma as "a taboo in all of society, not just the church. I think it's like any sort of social stigma. The way to remove stigma of mental health is to bring it out into the open. The only way to remove the stigma is to address it." Similarly, Reverend Lee (White female UMC) noted that "mental health is one thing that a lot of pastors don't talk about. But Jesus talked about mental health. He talked about our need for relief in mental health and who we can get past worry and anxiety. I like to talk about emotional and mental health because Jesus talked about. Because, to me, Jesus was one of the most practical teachers there ever was."

Participants emphasized the importance of framing their messages appropriately and presenting an image of themselves as role models for mental health (impression management). Pastor Randolph (White male SBC) explained that "clergy are role models whether they want to be or not. And when it comes to health and dealing with things like depression, our members are looking to us for how we talk about and handle things." Pastor Russell (White male E) added "I have to be a role model because I know people are watching me. I do it for me and I do it for them because I understand how the psychosomatic impacts of my spiritual and emotional well-being can impact me physically."

Participants also discussed the importance of bringing more action to responding to mental health in their congregations. For example, Pastor Lawrence argued that "people need more than just encouraging word or scripture. People need someone to help them to identify their problems and to develop a solution so that they can be more mentally healthy." Additionally, more than three-quarters of participants indicated that they would be interested in gaining access to educational resources for themselves and their congregations, suggesting that knowledge could combat stigma. Clergies indicated that their awareness of the problem of mental illness stigma is not adequate in addressing it in their congregations and that they need knowledge and resources from external sources to translate their interest and awareness into effective action.

\section{Discussion}

One contribution of this study is the elaboration on clergies' perspectives on mental health and stigma in congregations. Most participants recognized that mental health 
issues were present as important issues in their congregations. Research shows that stigma is a major barrier influencing whether mental health is addressed by clergies and faith communities (Blank et al. 2002; Neighbors et al. 1998). Many clergies in this study recognized the effects of stigma on perceptions of mental illness and how stigma influences whether people seek and receive help for mental health issues. In line with much of the previous literature, the Black clergies expressed an understanding that their views on mental health and illness were nuanced due to socio-cultural and historical differences. Help-seeking may be especially impeded for African American churchgoers due to a double stigma created by racial prejudice and discrimination in addition to the primary stigma associated with having symptoms of mental illness (Gary 2005). Study findings about the nuanced views of mental health among African American clergies show that mental illness remains a major concern in Black churches and further stress the importance of the Black church in addressing mental health and its impact on the African American community (Brewer and Williams 2019).

With this understanding and sensitivity to existing stigma, both Black and White clergies indicated a desire or actual efforts to confront mental health stigma in their congregations through open discussion and education. In their attempts to promote mental health, several participants used a combination of communication strategies, especially through supporting their messages with scripture and the use of language. A study on African American clergies found that participants wanted more information about depression and access to referral sources, resources that they linked to reducing mental health stigma. Another finding is that clergies often reported that they saw themselves as potential role models for mental health, including normalizing the discussion of struggling with mental health issues. In fact, Corrigan (2019) suggests that the messenger maybe the most important aspect of reducing stigma, and this is particularly important when the person delivering the message also has lived experience, as was the case for some of the participants in this study. An application of this can be seen in a recent mental health promotion campaign using clergies as messengers to reach African Americans (Thompkins et al. 2020).

How clergies communicate about mental health depends on a host of factors that determine how their beliefs are developed and acted upon. From the perspectives of the health belief model alongside the socioecological model, clergy beliefs and subsequent communication about mental health are influenced by a complex web of determinants including, but not limited to, individual, family, educational, church-level, denominational, theological, and societal factors. For example, the theological formation of clergies certainly may influence their understandings and communication. In this study, one female pastor discussed how liberation theology informed her approach to discussing mental health with parishioners, and one male participant discussed how teachings in seminary informed his ideas about addressing mental health. However, theological formation was otherwise not discussed by participants as a salient theme, even though theological concerns are likely influential. More commonly, clergies in this study chose to focus more on mental health experiences that affected themselves, their family members, or their congregants and how those experiences shaped their ideas and actions. An additional concern is that mental illness is a social construct developed in relation to social norms, which vary considerably by sociocultural context. Therefore, the perspectives of the clergies in this study may be quite different from those in other contexts.

Clergies expressed understandings of mental health as being integrally related to physical and spiritual health. This holistic view of mental health follows the major theme found in Holt and McClure's (Holt and McClure 2006) study of African American churchgoers and pastors. In another qualitative study, Baptist pastors similarly endorsed a holistic perspective, with one saying mental health is a "pluralistic interaction that involves the mind, body, and soul" (Stansbury et al. 2011).

The subtheme of code words and language in clergy interviews mirrors studies of African American congregations. One such study included reports from Black mental 
health consumers that they had been exposed to stigmatizing beliefs about mental illness and they connected mental illness, including anxiety and depression, to being crazy, and something that should not be shared with others (Alvidrez et al. 2008).

Although participants expressed great concern about mental health in their congregations, very few formal mental health services were offered. Only three participants reported having mental health programs or counselors available for their congregants including one large Baptist, one large Methodist, and one medium-sized Catholic church, all of which were predominantly White congregations. None of the Black churches in this study had formal mental health services, although a couple of them did serve as meeting locations for self-help groups, such as Alcoholics Anonymous and Narcotics Anonymous. These findings do not reflect some past research on the subject. For example, a survey of 269 churches found that Black churches had many more mental health services than White churches (Blank et al. 2002). The lack of formal mental health services in this sample of mostly small to medium congregations may be due to a lack of financial resources or expertise to support such programming.

The focus on formal mental health services may overlook the importance of informal assistance, such as being able to approach clergy members about mental and emotional concerns, receiving support from other congregants, or being referred to a mental health professional. Some clergies spoke of wanting to have a counseling service available to their members, but this has not yet occurred. In general, clergies expressed a perceived need for increased attention to mental health concerns in their congregations, and this may reflect the actual needs of their congregants. In a study by Hale and Bennett (Hale and Bennett 2003), over $80 \%$ of congregants surveyed believed that there was an unmet need for mental health care in their congregations that could be remedied specifically by implementing depression care and support groups. The same study found that $72 \%$ of clergies reported that it was very important for churches to actively address the health needs of congregations, with the remaining $28 \%$ reporting it was somewhat important.

Most clergies in this study reported that people come to them for assistance with a variety of issues, including mental and emotional issues. While they try to address these issues as much as possible from spiritual and practical standpoints, they were quick to point out that there is a limit to their roles and believed that certain mental health issues are best addressed through referral to a mental health professional. Stansbury and Schumacher (Stansbury and Schumacher 2008) found in interviews that clergies actively assisted congregants with mental health concerns but also shared a similar recognition of their limitations and the need for referral when their limits are exceeded. Neighbors and colleagues argued that clergies may be effective in reducing their congregants' perceived need for mental health professional care through the pastoral care they provide and, therefore, are less likely to refer people for external care. They added, however, that most clergies were willing to make referrals and act as "a bridge to mental health care" (Neighbors et al. 1998). This idea has been echoed more recently by scholars, confirming the potential role of religion and clergies in contributing to mental health in their communities (Hodge 2020) and specifically applied to the idea that African American faith leaders can be key referral sources and can thus contribute to improved mental health in Black communities (Scribner et al. 2020).

Participants indicated a number of communication skills and strategies that are necessary for responding to mental health issues. They emphasized the need for open, direct, non-judgmental communication that is culturally relevant in that it is based in biblical teachings and is respectful of the sociocultural characteristics of their congregants. Participants expressed confidence in their abilities to directly communicate such tailored messages. This aligns with Misra and colleagues' (Misra et al. 2021) recommendations for reducing stigma in racial and ethnic minority communities, including "moving into community settings, integrating cultural considerations, and targeting stigma directly" (Misra et al. 2021).

A surprising finding of this study is the perceived lack of resources available to clergies to help them discuss mental health topics. Participants consistently described a need for 
information and materials that could support them in addressing mental health stigma. Although resources specifically tailored to faith leaders about mental health are publicly available online, participants in this study were not aware of them (e.g., mentalhealth.gov or samhsa.gov). It appears that clergies possess the communication skills for addressing mental health and stigma but need more specific knowledge to effectively accomplish the task. Outreach efforts should involve providing mental health, treatment, and support information to interested clergies. Findings from this study independently highlight the need for research focused on the development of collaborative partnerships among clergies, congregations, health organizations, and academic health centers so that mental health information, knowledge, and resources are disseminated to those who need them. Similarly, a recent review of mental health and stigma interventions in Black faith settings emphasized the need to develop community partnerships to improve mental health and reduce stigma in minority populations (Codjoe et al. 2021).

While a strength of this study is in its focus on African American clergies' perceptions of mental health in congregations, one limitation is that clergies of other ethnic groups were excluded. Mental health stigma is an important concern for all communities, including ethnic minority communities, such as Latino and Asian American communities (Gary 2005; Uebelacker et al. 2012), and religious minority groups, such as Muslim communities (Ciftci et al. 2013). Future research should expand to explore perceptions of mental health and stigma in these populations.

\section{Conclusions}

Findings from this study add to the literature on mental illness and stigma in congregations in a number of ways. First, the context of the study in an urban area in the Deep South of the United States involving both Black and White clergy participants is unique to the literature. Previously, there was limited information about White clergies' perspectives on mental health, and this study bridges this gap by comparing them to the experiences of Black clergies. Furthermore, this study provides more evidence of the connections among religion, clergies, and mental health and illness in the context of congregations. Findings reveal new information about changing clergy perspectives, including a more widespread notion of mental health from a holistic standpoint and shifting understandings of depression being a common and treatable medical concern. However, according to clergies in this study, the problems of mental health stigma and treatment hesitancy remain problematic, and these concerns were more often expressed and more salient among Black clergies.

Finally, this study provides additional insight for developing church-based interventions for improving mental health and reducing mental illness stigma. Participants in this study confirmed that clergies are a key messenger of ideas related to mental health, and they recognized their significant influence on the beliefs and behaviors of their congregations. Clergies reported having the willingness and ability to communicate messages about mental health. However, they emphasized a great need to acquire additional knowledge and resources to do so effectively. Simply having awareness of a problem and interest in solving it do not translate into effective action-targeted information and resources are needed to support them. New faith-health collaborations will be needed to equip clergies with important information and resources regarding addressing mental health and stigma in their congregations.

Mental health, illness, and stigma have been perennial concerns in churches and communities, but recent developments such as the COVID-19 pandemic will exert even greater pressure on mental health concerns. How clergies respond to these situations will undoubtedly influence mental health outcomes in their congregations.

Funding: This research was funded by the Agency for Healthcare Research and Quality (AHRQ), grant number 5T32HS013852. 
Institutional Review Board Statement: The study was conducted according to the guidelines of the Declaration of Helsinki, and approved by the Institutional Review Board of the University of Alabama at Birmingham (protocol \# X141111006 11/13/2014).

Informed Consent Statement: Informed consent was obtained from all study participants.

Acknowledgments: The author would like to thank the participants for their contributions to the study.

Conflicts of Interest: The author declares no conflict of interest.

\section{References}

Alvidrez, Jennifer, Lonnie R. Snowden, and Dawn M. Kaiser. 2008. The Experience of Stigma among Black Mental Health Consumers. Journal of Health Care for the Poor and Underserved 19: 874-93. [CrossRef]

Anshel, Mark H., and Mitchell Smith. 2014. The Role of Religious Leaders in Promoting Healthy Habits in Religious Institutions. Journal of Religion and Health 53: 1046-59. [CrossRef] [PubMed]

Anthony, Jean S., April Johnson, and John Schafer. 2015. African American Clergy and Depression: What They Know; What They Want to Know. Journal of Cultural Diversity 22: 118-26. [PubMed]

Baruth, Meghan, Melissa Bopp, Benjamin L. Webb, and Jane A. Peterson. 2015. The Role and Influence of Faith Leaders on HealthRelated Issues and Programs in Their Congregation. Journal of Religion and Health 54: 1747-59. [CrossRef]

Blank, Michael B., Marcus Mahmood, Jeanne C. Fox, and Thomas Guterbock. 2002. Alternative Mental Health Services: The Role of the Black Church in the South. American Journal of Public Health 92: 1668-72. [CrossRef]

Bopp, Melissa, Meghan Baruth, Jane A. Peterson, and Benjamin L. Webb. 2013. Leading Their Flocks to Health? Clergy Health and the Role of Clergy in Faith-Based Health Promotion Interventions. Faith E Community Health 36: 182-92.

Brewer, LaPrincess C., and David R. Williams. 2019. We've Come This Far by Faith: The Role of the Black Church in Public Health. American Journal of Public Health 109: 385-86. [CrossRef]

Bronfenbrenner, Urie. 1979. The Ecology of Human Development: Experiments by Nature and Design. Cambridge: Harvard University Press.

Campbell, Marci Kramish, Marlyn Allicock Hudson, Ken Resnicow, Natasha Blakeney, Amy Paxton, and Monica Baskin. 2007. Church-Based Health Promotion Interventions: Evidence and Lessons Learned. Annual Review of Public Health 28: 213-34. [CrossRef] [PubMed]

Campbell, Rosalyn Denise, and Madison Rose Winchester. 2020. Let the Church Say: One Congregation's Views on How the Black Church Can Address Mental Health with Black Americans. Social Work E Christianity 47: 105-22.

Casados, Ava T. 2017. Reducing the Stigma of Mental Illness: Current Approaches and Future Directions. Clinical Psychology Science and Practice 24: 306. [CrossRef]

Charmaz, Kathy. 2006. Constructing Grounded Theory: A Practical Guide through Qualitative Analysis. Thousand Oaks: Sage.

Ciftci, Ayse, Nev Jones, and Patrick W. Corrigan. 2013. Mental Health Stigma in the Muslim Community. Journal of Muslim Mental Health 7. [CrossRef]

Cnaan, Ram A., and Daniel W. Curtis. 2013. Religious Congregations as Voluntary Associations: An Overview. Nonprofit and Voluntary Sector Quarterly 42: 7-33. [CrossRef]

Codjoe, Louisa, Sarah Barber, Shalini Ahuja, Graham Thornicroft, Claire Henderson, Heidi Lempp, and Joelyn N'Danga-Koroma. 2021. Evidence for Interventions to Promote Mental Health and Reduce Stigma in Black Faith Communities: Systematic Review. Social Psychiatry and Psychiatric Epidemiology 56: 895-911. [CrossRef]

Corrigan, Patrick. 2004. How Stigma Interferes with Mental Health Care. American Psychologist 59: 614-25. [CrossRef] [PubMed]

Corrigan, Patrick W. 2019. When the Medium Is the Best Message for Stigma Change. Stigma and Health 4: 365-66. [CrossRef]

Corrigan, Patrick, Brian McCorkle, Bonnie Schell, and Kathryn Kidder. 2003. Religion and Spirituality in the Lives of People with Serious Mental Illness. Community Mental Health Journal 39: 487-99. [CrossRef]

Gary, Faye A. 2005. Stigma: Barrier to Mental Health Care among Ethnic Minorities. Issues in Mental Health Nursing 26: 979-99. [CrossRef] [PubMed]

Hale, W. Daniel, and Richard G. Bennett. 2003. Addressing Health Needs of an Aging Society Through Medical-Religious Partnerships: What Do Clergy and Laity Think? The Gerontologist 43: 925-30. [CrossRef]

Hays, Krystal. 2018. Reconceptualizing Church-Based Mental Health Promotion with African Americans: A Social Action Theory Approach. Journal of Religion E Spirituality in Social Work: Social Thought 37: 351-72. [CrossRef]

Hill, Terrance D., Christopher G. Ellison, Amy M. Burdette, and Mark A. Musick. 2007. Religious Involvement and Healthy Lifestyles: Evidence from the Survey of Texas Adults. Annals of Behavioral Medicine 34: 217-22. [CrossRef]

Hodge, David R. 2020. Religious Congregations: An Important Vehicle for Alleviating Human Suffering and Fostering Wellness. Journal of Religion E Spirituality in Social Work: Social Thought 39: 119-37. [CrossRef]

Holt, Cheryl L., and Stephanie M. McClure. 2006. Perceptions of the Religion-Health Connection Among African American Church Members. Qualitative Health Research 16: 268-81. [CrossRef] [PubMed]

Janz, Nancy K., and Marshall H. Becker. 1984. The Health Belief Model: A Decade Later. Health Education Quarterly 11: 1-47. [CrossRef] 
Kousoulis, Antonis A., and Isabella Goldie. 2021. A Visualization of a Socio-Ecological Model for Urban Public Mental Health Approaches. Frontiers in Public Health 9. [CrossRef] [PubMed]

Laws, Terri. 2018. Tuskegee as Sacred Rhetoric: Focal Point for the Emergent Field of African American Religion and Health. Journal of Religion and Health 57: 408-19. [CrossRef]

Levin, J. 2010. Religion and Mental Health: Theory and Research. International Journal of Applied Psychoanalytic Studies 7: 102-15. [CrossRef]

Levin, Jeffrey S. 1984. The Role of the Black Church in Community Medicine. Journal of the National Medical Association 76: 477-83.

Mayer, Lea, Patrick W. Corrigan, Daniela Eisheuer, Nathalie Oexle, and Nicolas Rüsch. 2021. Attitudes towards Disclosing a Mental Illness: Impact on Quality of Life and Recovery. Social Psychiatry and Psychiatric Epidemiology, 1-12. [CrossRef] [PubMed]

Misra, Supriya, Valerie W. Jackson, Jeanette Chong, Karen Choe, Charisse Tay, Jazmine Wong, and Lawrence H. Yang. 2021. Systematic Review of Cultural Aspects of Stigma and Mental Illness among Racial and Ethnic Minority Groups in the United States: Implications for Interventions. American Journal of Community Psychology. [CrossRef]

Moreira-Almeida, Alexander, Francisco L. Neto, and Harold G. Koenig. 2006. Religiousness and Mental Health: A Review. Brazilian Journal of Psychiatry 28: 242-50. [CrossRef]

Neighbors, Harold W., Marc A. Musick, and David R. Williams. 1998. The African American Minister as a Source of Help for Serious Personal Crises: Bridge or Barrier to Mental Health Care. Health Education \& Behavior 25: 759-77.

Oxhandler, Holly K., Sarah C. Narendorf, and Kelsey M. Moffatt. 2018. Religion and Spirituality among Young Adults with Severe Mental Illness. Spirituality in Clinical Practice 5: 188-200. [CrossRef]

Parcesepe, Angela M., and Leopoldo J. Cabassa. 2013. Public Stigma of Mental Illness in the United States: A Systematic Literature Review. Administration and Policy in Mental Health and Mental Health Services Research 40: 384-99. [CrossRef] [PubMed]

Payán, Denise D., Karen R. Flórez, Malcolm V. Williams, Clyde W. Oden, Michael A. Mata, Cheryl A. Branch, Margaret D. Whitley, and Kathryn P. Derose. 2021. Sermons to Address Obesity in Partnership With African American and Latino Churches. Journal of Nutrition Education and Behavior 53: 811-15. [CrossRef]

Peteet, John R. 2019. Approaching Religiously Reinforced Mental Health Stigma: A Conceptual Framework. Psychiatric Services 70: 846-48. [CrossRef] [PubMed]

Rasic, Daniel, Jennifer A. Robinson, James Bolton, O. Joseph Bienvenu, and Jitender Sareen. 2011. Longitudinal Relationships of Religious Worship Attendance and Spirituality with Major Depression, Anxiety Disorders, and Suicidal Ideation and Attempts: Findings from the Baltimore Epidemiologic Catchment Area Study. Journal of Psychiatric Research 45: 848-54. [CrossRef]

Salganik, Matthew J., and Douglas D. Heckathorn. 2004. Sampling and Estimation in Hidden Populations Using Respondent-Driven Sampling. Sociological Methodology 34: 193-240. [CrossRef]

Scribner, Susan S., Robert F. Poirier, Wendy Orson, Rose Jackson-Beavers, Booker T. Rice, Karl Wilson, and Barry A. Hong. 2020. Bridges to Care and Recovery: Addressing Behavioral Health and Mental Health Needs Through the Faith Community. Journal of Religion and Health 59: 1946-57. [CrossRef] [PubMed]

Skinner, Celeste Sugg, Jasmin Tiro, and Victoria L. Champion. 2015. Background on the Health Belief Model. In Health Behavior: Theory, Research, and Practice, 5th ed. San Francisco: Jossey Bass, p. 75.

Stansbury, Kim, and Mitzi Schumacher. 2008. An Exploration of Mental Health Literacy Among African American Clergy. Journal of Gerontological Social Work 51: 126-42. [CrossRef] [PubMed]

Stansbury, Kim L., Blake Beecher, and Mary Ann Clute. 2011. African American Clergy's Perceptions of Mental Health and Pastoral Care to Elder Congregants. Journal of Religion \& Spirituality in Social Work: Social Thought 30: 34-47. [CrossRef]

Sternthal, Michelle J., David R. Williams, Marc A. Musick, and Anna C. Buck. 2010. Depression, Anxiety, and Religious Life: A Search for Mediators. Journal of Health and Social Behavior 51: 343-59. [CrossRef]

Thompkins, Floyd, Peter Goldblum, Tammy Lai, Tristan Hansell, Annanda Barclay, and Lisa M. Brown. 2020. A Culturally Specific Mental Health and Spirituality Approach for African Americans Facing the COVID-19 Pandemic. Psychological Trauma: Theory, Research, Practice, and Policy 12: 455-56. [CrossRef] [PubMed]

Uebelacker, Lisa A., Beth A. Marootian, Paul A. Pirraglia, Jennifer Primack, Patrick M. Tigue, Ryan Haggarty, Lavinia Velazquez, Jennifer J. Bowdoin, Zornitsa Kalibatseva, and Ivan W. Miller. 2012. Barriers and Facilitators of Treatment for Depression in a Latino Community: A Focus Group Study. Community Mental Health Journal 48: 114-26. [CrossRef]

Ward, Earlise C., Jacqueline C. Wiltshire, Michelle A. Detry, and Roger L. Brown. 2013. African American Men and Women's Attitude toward Mental Illness, Perceptions of Stigma, and Preferred Coping Behaviors. Nursing Research 62: 185-94. [CrossRef] [PubMed]

Webb, Benjamin, Melissa Bopp, and Elizabeth A. Fallon. 2011. Factors Associated with Obesity and Health Behaviors among Clergy. Journal of Religion and Health 52: 235-46. [CrossRef] [PubMed]

Wesselmann, Eric D., and William G. Graziano. 2010. Sinful and/or Possessed? Religious Beliefs and Mental Illness Stigma. Journal of Social and Clinical Psychology 29: 402-37. [CrossRef]

West, Donnie W., Susie Tanamly, Judith Novgrod, Eugene Williams, Lorrie Bisesi, Cheryl A. Branch, and Tiffanie Sim. 2006. AfricanAmerican Clergy's Perceptions of the Leading Health Problems in Their Communities and Their Role in Supporting Parishioners' Health. The Journal of Pastoral Care \& Counseling 60: 13-25.

Wong, Eunice C., Kathryn P. Derose, Paula Litt, and Jeremy N. V. Miles. 2018. Sources of Care for Alcohol and Other Drug Problems: The Role of the African American Church. Journal of Religion and Health 57: 1200-10. [CrossRef] 